\title{
An Equilateral Arm Inverted U-Slot and Notch Loaded UWB-CPMA with Rendered Ground Plane
}

\author{
Mukesh Kumar, Jamshed Aslam Ansari, Abhishek K. Saroj, Rohini Saxena
}

\begin{abstract}
In this paper, a microstrip fed modified circular patch monopole antenna (CPMA) with the rendered ground surface is presented for bandwidth enhancement. In order to extend the bandwidth of a demonstrated antenna, symmetrical slots and equilateral arms inverted $U$-slot are loaded on the partial ground and patch individually. For additional enhancement in the secured bandwidth, symmetrical notches are truncated from the bottom of the patch. The antenna has a

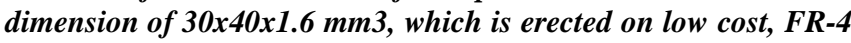
substrate with relative permittivity $\epsilon_{r}=4.4$, permeability $\mu=1$ and loss tangent of $\tan \delta=0.02$. The proposed design is analyzed and simulated using high frequency structure simulator (HFSS). The analyzed results are validated through experimented results. The proposed antenna offers a bandwidth of $140.2 \%$ with a maximum radiation efficiency of $94 \%$ over the frequency scope of $2.54 \mathrm{GHz}$ to $14.47 \mathrm{GHz}$. The crosspolarization levels are also found to be 20-30 $\mathrm{dB}$ and 12-23 $\mathrm{dB}$ smaller than the co-polarized level for E-plane and H-plane respectively. For better execution and assessment of proposed antenna, a parametric study has been done to analyze the performance of antenna with variations in the length of a partial ground conductor beside the other parameters. The exhibited antenna is suitable for various applications incorporating WiMAX, WLAN, UWB, C-band, $X$-band and UWB.
\end{abstract}

Keywords: CPMA, MPA, MSA, UWB, Rendered Ground, Bandwidth Enhancement, Radiation Efficiency.

\section{INTRODUCTION}

Microstrip patch antennas (MPAs) are expeditiously expanded in the ultra wide band (UWB) system applications. The Federal Communication Commission (FCC) allocated UWB frequency scope from $3.1-10.6 \mathrm{GHz}$ for commercial applications [1-3]. It has salient features like huge bandwidth, less power consumption, simple hardware configuration that support high data rate primarily in shortrange wireless technology for the wireless multimedia system, biomedical system, modern communication system, etc. [4]. There are different kinds of structure and techniques have been developed to accomplish UWB attributes. Quite a few of these conventional MPAs do not cover the entire bandwidth [5- 8]. Recently, monopole MSAs have become more popular due to its facile geometry, wide bandwidth, stable radiation pattern and greater radiation efficiency [9].

Revised Manuscript Received on December 30, 2019.

* Correspondence Author

Mukesh Kumar*, Department of ECE, University of Allahabad, U.P, India. Email: mukesh044@gmail.com.

Jamshed Aalam Ansari, Department of ECE, University of Allahabad, U.P, India. Email: jaansari@rediffmail.com.

Abhishek K. Saroj, Department of ECE, University of Allahabad, U.P, India. Email: abhisheksaroj@gmail.com.

Rohini Saxena, Department of ECE, University of Allahabad, U.P, India. Email: rohini.saxena@gmail.com.

(c) The Authors. Published by Blue Eyes Intelligence Engineering and Sciences Publication (BEIESP). This is an open access article under the CC BY-NC-ND license (http://creativecommons.org/licenses/by-nc-nd/4.0/)
Numerous geometries of monopole MPAs have been investigated for UWB applications such as microstrip fed circular patch antenna utilizing a partial ground surface for UWB operations with stable radiation characteristics [1011]. Wide Band behaviour is reported due to circular- square linked notch [12] and Saturn-shaped notch [13] on the partial ground surface with slotted circular disk monopole antenna. An electrically small size coplanar waveguide (CPW) fed circular disk monopole antenna provided very large impedance bandwidth with a flat gain [14]. Bandwidth enlargement of the MPA is obtained through impedance matching by the appropriate amending the gap between radiating element and ground surface [15-17]. A modified square MPA is implemented to achieve wide band characteristics and stable radiation attribute along with appropriate cross-polarization level by the employing rectangular parasitic with the defected ground conductor [18]. Bandwidth expansion is accomplished by the properly adjusting couple of sleeves in the curved ground plane with elliptical patch monopole antenna [19]. Such a large bandwidth with high radiation efficiency is examined owing to the impedance matching by the appropriately embedding rectangular slot in a partial ground surface with annular ring monopole MPA [20] and with octagonal shape monopole MPA [21]. Broadband characteristics are achieved by loading a symmetrical rectangular slot in the partial ground conductor with symmetrical hexagonal monopole MPA [22]. A toppled trapezium-shaped monopole MPA is investigated which provide very large bandwidth along with high gain ranging from 7.1- $26 \mathrm{GHz}$ [23]. Super wide band performance is realized by reason of familiarizing fractal geometry on the radiating patch with truncated ground plane [24]. Notwithstanding, during the time spent expanding the bandwidth, the greater part of the plan winds up immense in size or complex in structure. The aim of proposed structure relies upon a monopole antenna configuration and above mentioned literature to study how to overcome the hindrance of restricted bandwidth and achieve better radiation characteristics. In this paper, an equilateral arm inverted U-slot and notch loaded UWB-CPMA with rendered ground plane are studied and analyzed. The demonstrated antenna is excited from a microstrip feedline by selecting appropriate locations and dimensions of slots and notches on the patch for extending the bandwidth. A parametric variation is additionally studied for geometrical expansion. The simulated and measured outcomes agree well. Pair of symmetrical notches are truncated from the base of the patch for further improvement on the bandwidth and radiation characteristics. 


\section{An Equilateral Arm Inverted U-Slot and Notch Loaded UWB-CPMA with Rendered Ground Plane}

The introduced antenna covers the frequency band from $2.54 \mathrm{GHz}$ to $14.47 \mathrm{GHz}$, which is approximately $140.2 \%$ impedance bandwidth. Table 1 shows that comparison between above-mentioned antennas and proposed antenna with their characteristics such as impedance bandwidth, gain, radiation efficiency along with substrate used for fabrication. Particulars of the antenna structure with their characteristics are illustrated in the next section.

TABLE 1: A comparison between previously published monopole antennas.

\begin{tabular}{|c|c|c|c|c|c|}
\hline Ref. & $\begin{array}{c}\text { Size } \\
\mathbf{( \mathbf { m m } ^ { 2 } )}\end{array}$ & Substrate & $\begin{array}{c}\text { Bandwidth } \\
\mathbf{( \% )}\end{array}$ & $\begin{array}{c}\text { Maximum } \\
\text { Gain (dB) }\end{array}$ & $\begin{array}{c}\text { Maximum } \\
\text { Efficiency (\%) }\end{array}$ \\
\hline $\mathbf{1 0 .}$ & $42 \times 50$ & FR-4 & 111.4 & 6.7 & Not Given \\
\hline $\mathbf{1 1 .}$ & $46 \times 52$ & FR-4 & 140 & 1.86 & 89.6 \\
\hline $\mathbf{1 2 .}$ & $22 \times 28$ & FR-4 & 117.3 & 4 & Not Given \\
\hline $\mathbf{1 3 .}$ & $18 \times 12$ & FR-4 & 114.5 & 2.04 & Not Given \\
\hline $\mathbf{1 4 .}$ & $35 \times 30$ & FR-4 & 146.3 & 5 & $>80 \%$ \\
\hline $\mathbf{1 5 .}$ & $46 \times 52$ & FR-4 & 145.7 & 1.55 & 87.88 \\
\hline $\mathbf{1 6 .}$ & $30 \times 30$ & FR-4 & 111.6 & 4.6 & Not Given \\
\hline $\mathbf{1 7 .}$ & $45 \times 50$ & FR-4 & 107.6 & 6 & 96 \\
\hline $\mathbf{1 8 .}$ & $20 \times 25$ & FR-4 & 110 & 5.1 & 89 \\
\hline $\mathbf{1 9 .}$ & $30 \times 35$ & FR-4 & 117.8 & 6 & 97 \\
\hline $\mathbf{2 0 .}$ & $39 \times 40$ & FR-4 & 129.3 & 5.52 & 91.2 \\
\hline $\mathbf{2 1 .}$ & $35 \times 35$ & FR-4 & 139 & $1.7-5$ & 95 \\
\hline $\mathbf{2 2 .}$ & $25 \times 20$ & FR-4 & 118.8 & 5.1 & Not Given \\
\hline $\mathbf{2 3 .}$ & $30 \times 40$ & Neltech & 114.2 & 8.24 & 85 \\
\hline $\mathbf{2 4 .}$ & $62 \times 64$ & FR-4 & 175.7 & 5.5 & 85 \\
\hline proposed & $30 \times 40$ & FR-4 & 140.2 & 4.75 & 94 \\
\hline
\end{tabular}

\section{GEOMETRICAL SPECIFICATIONS OF} ANTENNA

The outline of the implemented antenna with a rendered ground plane appears in Fig. 1. The antenna comprises of rectangular notched circular patch radiator with an inverted U-slot fed by 50-Ohms microstrip-line and a couple of horizontally symmetrical I-shaped slotted partial ground for bandwidth enhancement. The antenna is fabricated on FR-4 substrate with dielectric constant $\varepsilon_{r}=4.4$ and loss tangent $\tan \delta=0.02$. The radius of the patch is considered as $9 \mathrm{~mm}$ with $1.6 \mathrm{~mm}$ substrate height. The area of the substrate is $\mathrm{L}_{\mathrm{s}}$ $\mathrm{x} \mathrm{W}_{\mathrm{s}}$ with $17 \mathrm{~mm}$ of ground conductor.

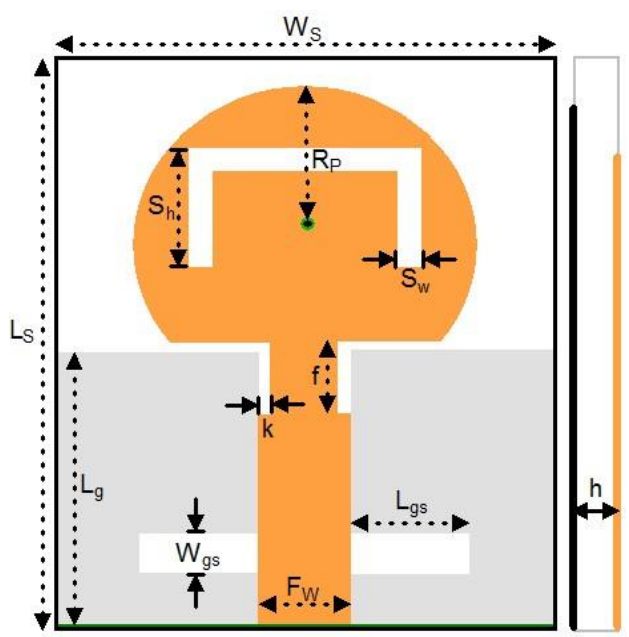

Fig.1. Geometrical layout of the proposed antenna.

TABLE 2: Geometrical specifications of an antenna.

\begin{tabular}{|l|l|l|l|l|l|l|}
\hline Parameters & Rp & Ws & Ls & Fw & h & Lg \\
\hline Dimensions(mm) & 9 & 30 & 40 & 4 & 1.6 & 17 \\
\hline Parameters & Sh & Sw & Wgs & Lgs & k & f \\
\hline Dimensions(mm) & 8 & 2 & 2 & 8 & 0.5 & 4 \\
\hline
\end{tabular}

The proposed geometrical specification of a demonstrated antenna is depicted in Table 2. The prototype of a fabricated antenna is exhibited in Fig. 2.

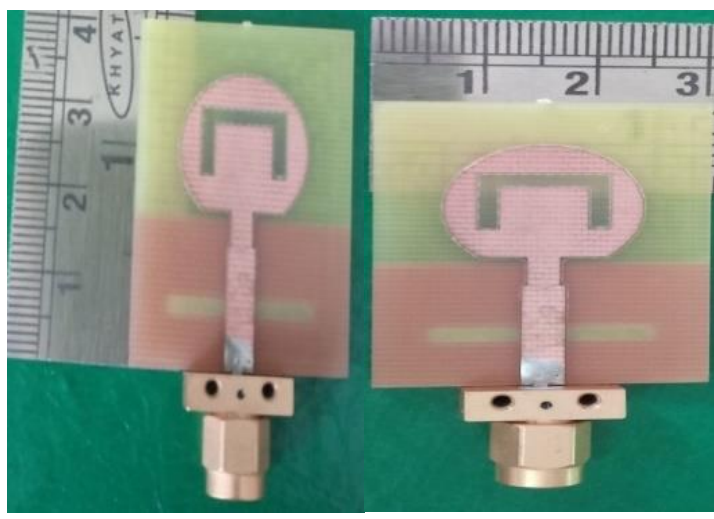

(a) (b)

Fig.2. (a) and (b) Dimension of fabricated antenna. 


\section{DESIGN PROCEDURE AND PERFORMANCE}

The evolution of the proposed antenna stages with their simulated performance in terms of reflection coefficient (S11 <-10) are described and presented in Fig. 3. In the beginning, three frequency bands, 3.29-4.72 GHz, 6.54-9.25 $\mathrm{GHz}$ and 10.6 - $14.28 \mathrm{GHz}$ are obtained, when a conventional edge fed circular patch with a finite ground conductor is selected with appropriate dimension. In the second stage, additional resonance is energized by the employing pair of horizontal I - shaped slots in the ground conductor and thus $74.15 \%$ impedance bandwidth is achieved ranging from $6.55-14.72 \mathrm{GHz}$.

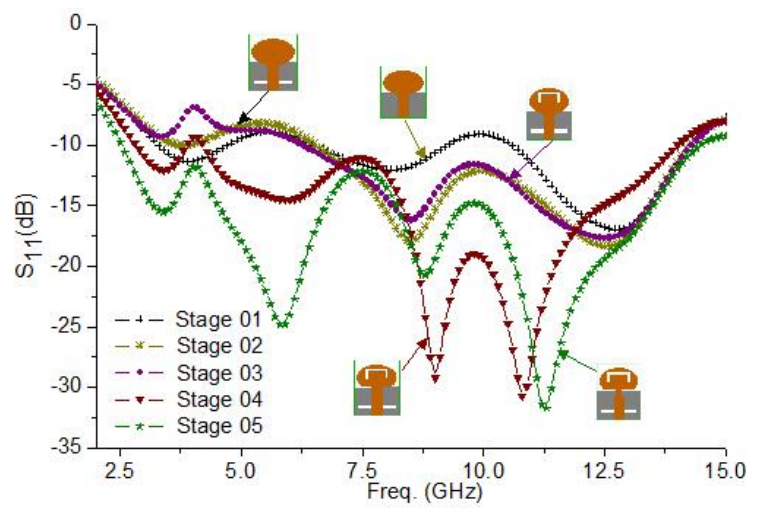

Fig.3. Simulated reflection coefficient of different stage.

For the instance of stage third, the current path length is increased when inverted $U$ - slot is loaded on the patch section, which results in shifting the resonance at the lower bands and the frequency band reaches up to $6.3 \mathrm{GHz}$ with $77.66 \%$ impedance bandwidth. For the excitation of the lower order resonance, the pair of notches are employed at the base of the radiator in the stage fourth. This gap generates strong coupling between patch and ground plane, which results provide good impedance matching with enriched bandwidth of $29.85 \%$ and $106.96 \%$ ranging from $2.85 \mathrm{GHz}$ - $3.85 \mathrm{GHz}$ and $4.24 \mathrm{GHz}$ - $13.99 \mathrm{GHz}$ individually. Finally, when pair of vertical I- shaped slots are incorporated in feed line at the base of the patch in the stage fifth, the additional resonance excited with better impedance matching, which provides $140.2 \%$ impedance bandwidth ranging from $2.54 \mathrm{GHz}$ to $14.47 \mathrm{GHz}$.

\section{PARAMETRIC STUDY}

In this section, a study of the various parameter of a demonstrated antenna is discussed and investigated sensitive parameters which are responsible for antenna performance. In the parametric study, only a single parameter is varied at a time while the others keep constant as given in Table 1 . The impact of reflection coefficient for different estimations of antenna parameters patch radius, ground length, ground slot length, arm height of inverted U-slot are introduced in Fig. 4.

In Fig. 4 (a), it could be observed significant variation in bandwidth and impedance matching when the patch radius $\left(R_{p}\right)$ is varied from $8 \mathrm{~mm}$ to $9 \mathrm{~mm}$ with $1 \mathrm{~mm}$ interim. Dual frequency behavior is achieved $(2.7-3.7 \mathrm{GHz}$ and $4 \mathrm{GHz}$ to 14.6 $\mathrm{GHz}$ ) at $8 \mathrm{~mm}$ patch radius.
When the radius of the patch is increased by $1 \mathrm{~mm}$, good impedance matching and bandwidth can be found and antenna radiated over the frequency range of $2.54 \mathrm{GHz}$ to 14.47 GHz with $140.2 \%$ bandwidth.

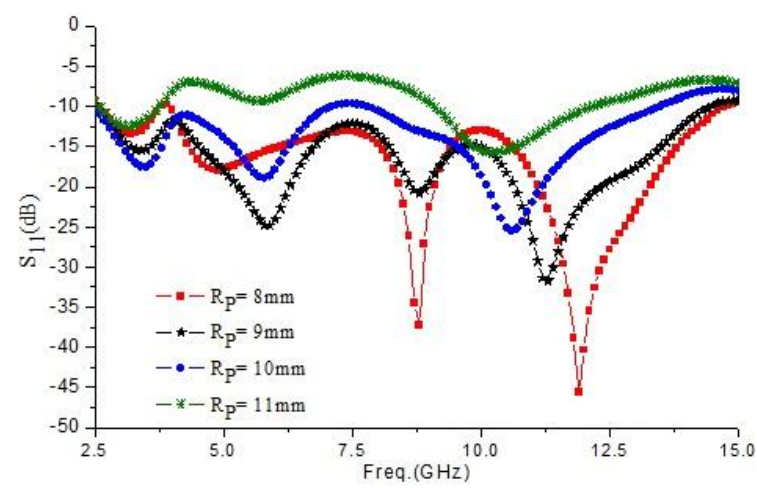

(a)

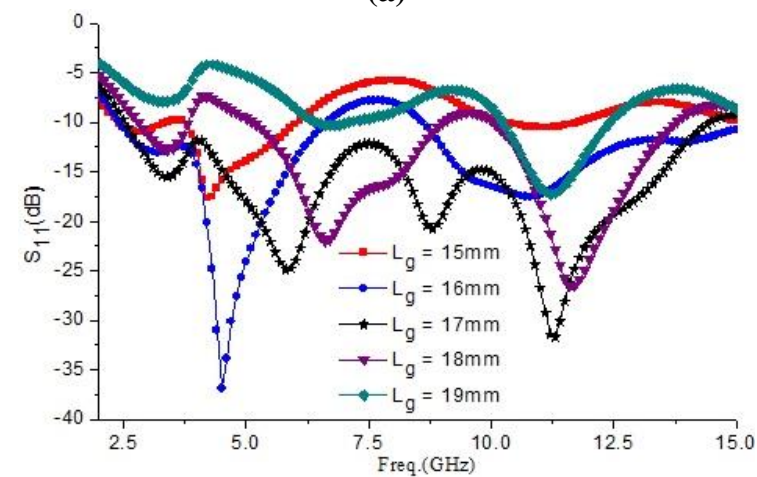

(b)

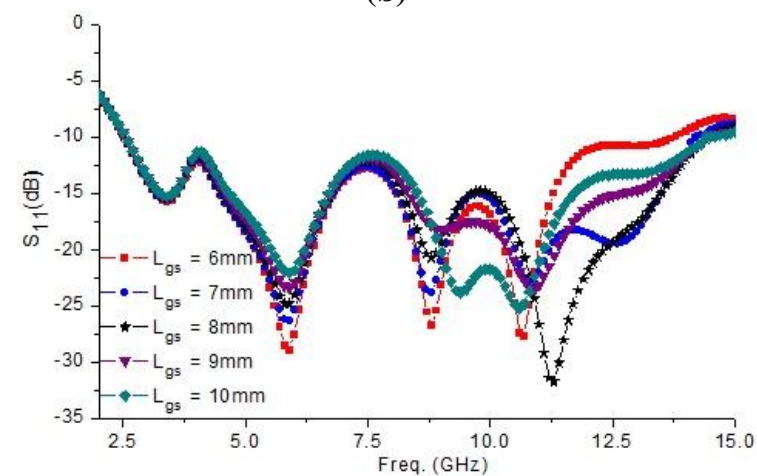

(c)

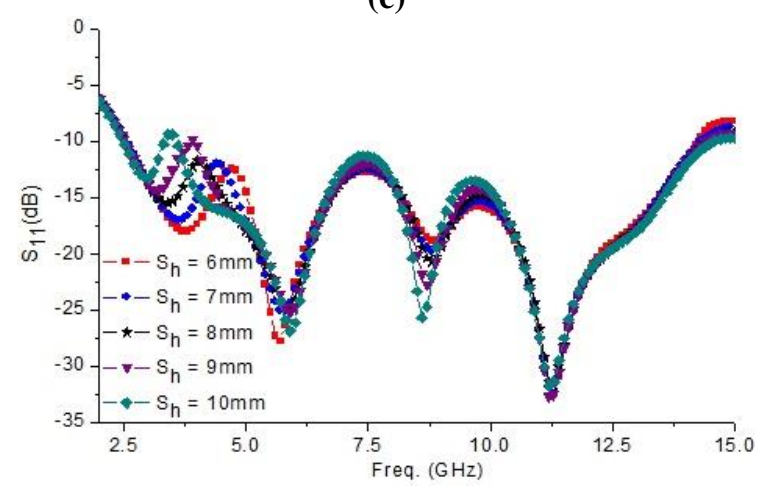

(d)

Fig.4. Simulated reflection coefficient variation for (a) $R_{p}$, (b) Lg, (c) Lgs, and (d) $S_{h}$. 
Impedance matching and bandwidth are affected for further increment in patch radius.

The variation of ground length $\left(\mathrm{Lg}_{\mathrm{g}}\right)$ from $15 \mathrm{~mm}$ to $19 \mathrm{~mm}$ with $1 \mathrm{~mm}$ interim is shown in Fig. 4 (b). We accomplish better impedance matching at $17 \mathrm{~mm}$ which provides improved bandwidth. Further variations in ground length degraded impedance matching and bandwidth.

The impact of ground slot length $\left(\mathrm{L}_{\mathrm{gs}}\right)$ deviation from 6 $\mathrm{mm}$ to $10 \mathrm{~mm}$ with an interval of $1 \mathrm{~mm}$ is exhibited in Fig. 4 (c). The impedance matching and bandwidth are slightly varied with slot length. The overall bandwidth achieved 11.1 $\mathrm{GHz}, 11.5 \mathrm{GHz}, 11.93 \mathrm{GHz}, 11.75 \mathrm{GHz}$ and $11.7 \mathrm{GHz}$ for the slot length at $6 \mathrm{~mm}, 7 \mathrm{~mm}, 8 \mathrm{~mm}, 9 \mathrm{~mm}$ and $10 \mathrm{~mm}$ respectively. At the optimum value of $8 \mathrm{~mm}$ achieved improved bandwidth.

Different frequency bands are observed for different estimation of arm height of the inverted U-slot $\left(\mathrm{S}_{\mathrm{h}}\right)$ from 6 $\mathrm{mm}$ to $10 \mathrm{~mm}$ with $1 \mathrm{~mm}$ gap and depicted in Fig. 4 (d). At the height of " $\mathrm{S}_{\mathrm{h}}=6 \mathrm{~mm}, 7 \mathrm{~mm}$ and $8 \mathrm{~mm}$ ", antenna radiated over the frequency scope of 2.6 to $14.2 \mathrm{GHz}, 2.6$ to 14.27 $\mathrm{GHz}$ and 2.54 to $14.47 \mathrm{GHz}$ respectively. At the height of " $\mathrm{S}_{\mathrm{h}}=6 \mathrm{~mm}, 7 \mathrm{~mm}$ and $8 \mathrm{~mm}$ ", antenna radiated over the frequency scope of 2.6 to $14.2 \mathrm{GHz}, 2.6$ to $14.27 \mathrm{GHz}$ and 2.54 to $14.47 \mathrm{GHz}$ respectively. As the height of " $\mathrm{S}_{\mathrm{h}}$ " is further increased from $8 \mathrm{~mm}$ to $9 \mathrm{~mm}$ and $9 \mathrm{~mm}$ to $10 \mathrm{~mm}$, antenna shows dual frequency bands from 2.55 to $3.8 \mathrm{GHz}$ and 4 to $14.4 \mathrm{GHz}$ as well as 2.5 to $3.3 \mathrm{GHz}$ and 3.6 to 14.6 $\mathrm{GHz}$ respectively. At the estimation of " $\mathrm{S}_{\mathrm{h}}=8 \mathrm{~mm}$ " accomplished maximum bandwidth.

From figure 4, parametric variations of different extents of the offered antenna are examined and perceived, and the gap between patch $\left(R_{p}\right)$ and ground length $\left(L_{g}\right)$ plays a significant role for acquiring wide band features. The length of the ground plane controls the coupling between the ground and the patch. It acts as an additional impedance matching network. The gap size influences the impedance matching and selecting proper gap between radiator and ground plane, results in smooth transition from one resonant mode to another resonant mode and confirming good impedance matching over a frequency range of $2.54 \mathrm{GHz}$ to 14.47 GHz.

\section{RESULT AND DISCUSSIONS}

The proposed antenna is fabricated on FR-4 substrate using CNC machine and measurement is carried out using Agilent Vector Network Analyzer E5071C. Fig. 5 (a) demonstrates the correlation between simulated and experimental reflection coefficient (S11) of the proposed antenna. The simulated and experimental results are slightly shifted due to fabrication tolerances and software limitations in terms of modelling and simulating over a large bandwidth from 2.54 to $14.47 \mathrm{GHz}$. Fig. 5 (b) and 5 (c) illustrate the comparison of simulated and experimental gain and radiation efficiency (\%) individually of the proposed antenna.

Gain is measured by two antenna strategy by utilizing horn antenna and proposed model antenna in an anechoic chamber. The maximum experimental gain of $4.75 \mathrm{~dB}$ at $10.9 \mathrm{GHz}$ is achieved with more than $74 \%$ radiation efficiency for the entire operating band.

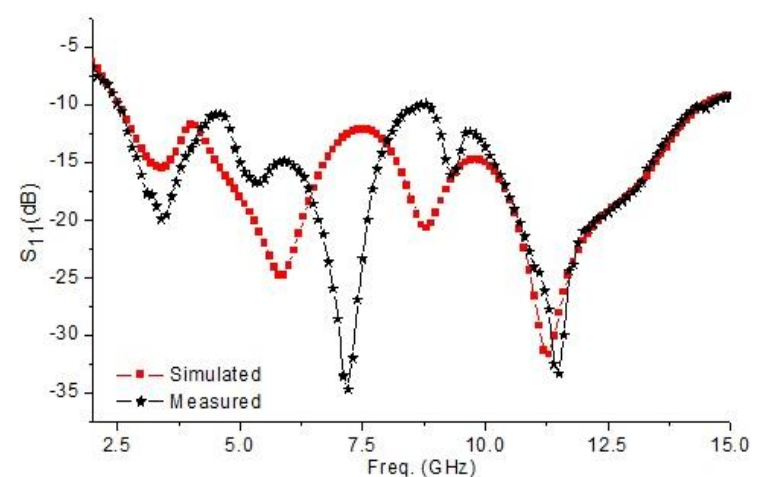

(a)

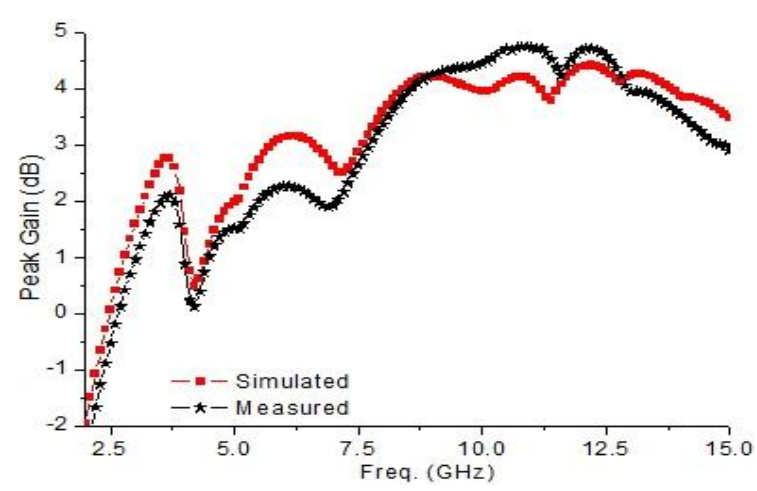

(b)

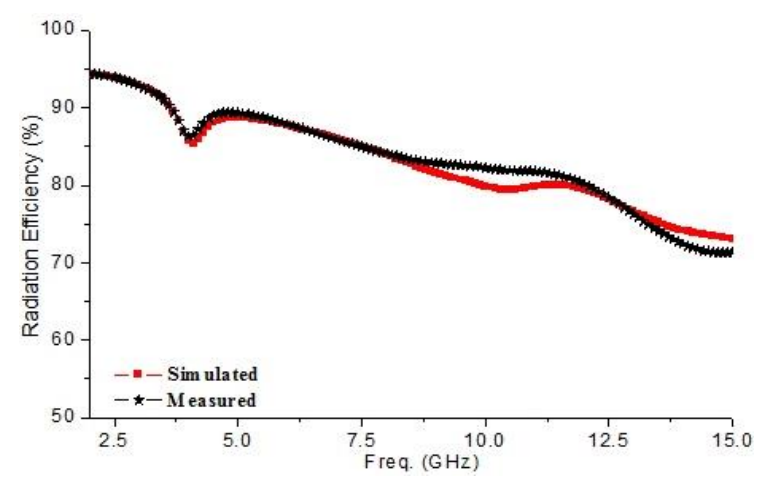

(c)

Fig.5. Comparison of simulated and measured results of the proposed antenna for (a) S11, (b) Gain, (c) Radiation efficiency.

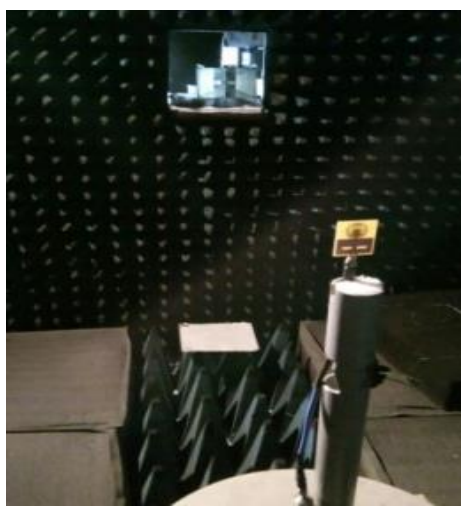

Fig.6. Proposed antenna in anechoic chamber.

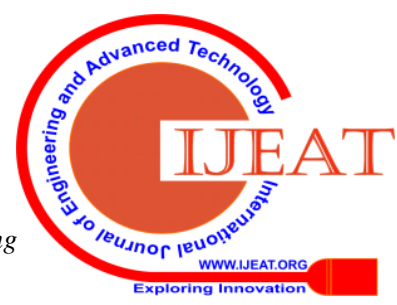


It is observed that the radiation efficiency gradually decreases from lower to higher frequencies. At higher frequencies dielectric losses increases which cause a reduction in radiation efficiency. Anechoic chamber arrangement for the proposed antenna is appeared in Figure 6.

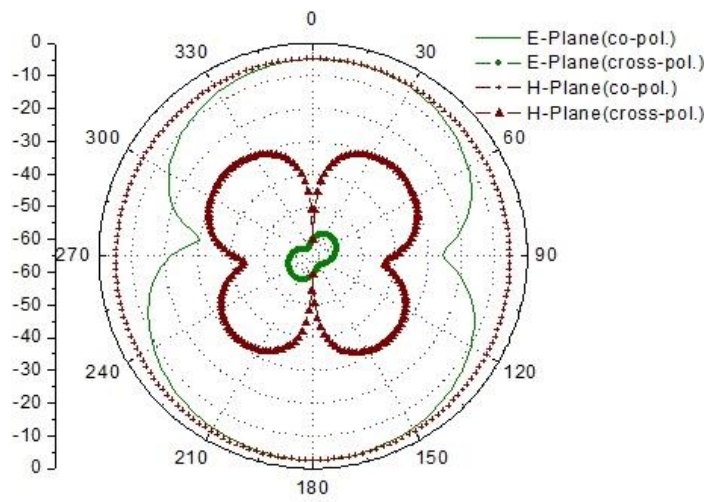

(a)

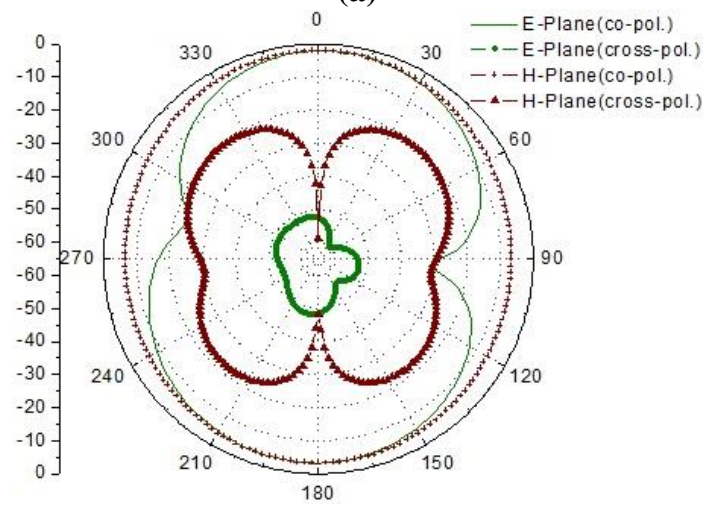

(b)

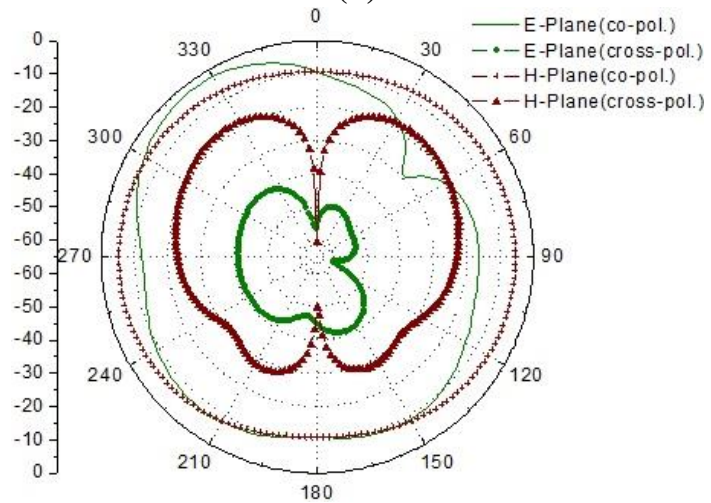

(c)

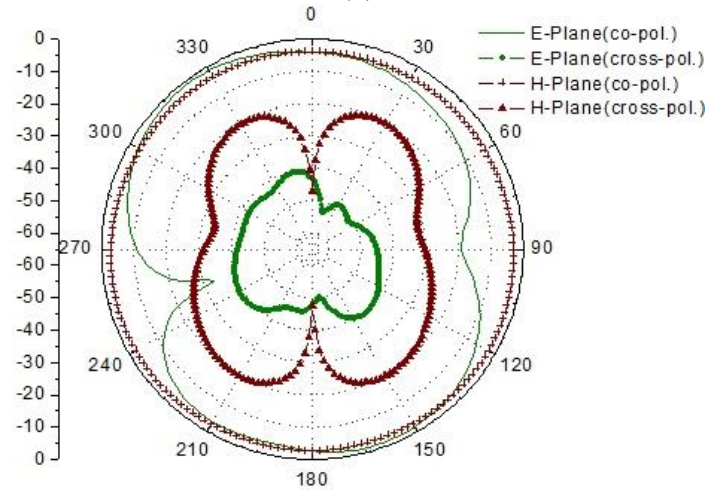

(d)

Fig.7. Simulated radiation pattern of proposed antenna at different resonant frequencies (a) $3.4 \mathrm{GHz}$, (b) $5.8 \mathrm{GHz}$, (c) $8.8 \mathrm{GHz}$ and (d) $11.3 \mathrm{GHz}$.
Fig. 7 (a), (b), (c) and (d) shows the simulated 2D radiation patterns of co-polarization and cross-polarization for E-plane and H-plane at resonating frequency of $3.4 \mathrm{GHz}$, $5.8 \mathrm{GHz}, 8.8 \mathrm{GHz}$ and $11.3 \mathrm{GHz}$ respectively.

The maximum cross-polarization level is $-56.9 \mathrm{~dB}$ and $28.4 \mathrm{~dB},-47.9 \mathrm{~dB}$ and $-20 \mathrm{~dB},-40 \mathrm{~dB}$ and $-17.9 \mathrm{~dB}$ as well as $-39 \mathrm{~dB}$ and $-19.7 \mathrm{~dB}$ at $3.4 \mathrm{GHz}, 5.8 \mathrm{GHz}, 8.8 \mathrm{GHz}$ and $11.3 \mathrm{GHz}$ respectively for E-plane and $\mathrm{H}$-plane. The crosspolarization values are 20-30 $\mathrm{dB}$ and $12-23 \mathrm{~dB}$ lower than the co-polarized values for E-plane and H-plane individually.

\section{CONCLUSION}

An inverted U-slot loading compact circular patch with the rendered ground plane is demonstrated for UWB applications. Due to selecting appropriate locations and dimensions of notch and slots on the patch and ground plane, bandwidth of the introduced antenna is expanded. The simulated and experimental results of the presented antenna are agreeable over the operating frequency scope of $2.54 \mathrm{GHz}$ to $14.47 \mathrm{GHz}$. Peak gain of $4.75 \mathrm{~dB}$ and peak radiation efficiency of $94 \%$ have been achieved along with stable radiation attributes for the demonstrated antenna. From an aggregate perspective on radiation patterns, the antenna acts correspondingly to the ordinary printed monopoles. All the above properties demonstrate that the proposed antenna is proficient to deal with the necessities of UWB operations.

\section{REFERENCES}

1. FCC First Report and Order on the Ultra-wideband Technology, Federal Communication Commission, Washington, DC, USA, April 2002

2. R. S. Kshetrimayum, "An introduction to UWB communication systems," IEEE Potentials, vol. 28, issue 2, April 2009, pp. 9 - 13.

3. A. F. Molisch, "Ultra-wide-band propagation channels," Proceedings of the IEEE, vol. 97, issue 2, Feb. 2009, pp. 353-371.

4. K. P. Ray, S. S. Thakur, and S. S. Kakatkar, "Bandwidth Enhancement Techniques for Printed Rectangular Monopole Antenna," IETE Journal of Research, vol. 60, no. 3, July 2014, pp. 249-256.

5. J. A. Ansari, K. Kumari, A. Singh, and A. Mishra, "Ultra Wideband Co-planer Microstrip Patch Antenna for Wireless Applications", Wireless Personal Communications, vol. 69, issue 4, May 2012, pp. 1365-1378, .

6. A. A. L. Neyestanak, "Ultra Wideband Rose Leaf Microstrip Patch Antenna”, PIER, vol. 86, 2008, pp. 155-168.

7. G. P. Pandey, B. K. Kanaujia, A. K. Gautam, and S. K. Gupta, "UltraWideband L-Strip Proximity Coupled Slot Loaded Circular Microstrip Antenna for Modern Communication Systems", Wireless Personal Communications, vol. 70, issue 1, June 2012, pp. 139-151.

8. F. G. Kharakhili, M. Fardis, G. Dadashzadeh, and A. Ahmadi, "Circular Slot with a novel Circular Microstrip open ended Microstrip Feed for UWB applications”, PIER, vol. 68, 2007, pp. 161-167.

9. M. Kumar, J. A. Ansari, A. K. Saroj, R. Saxena, and Devesh, "A novel microstrip fed L-shaped arm slot and notch loaded RMPA with mended ground plane for bandwidth improvement" PIER C, vol. 95, 2019, pp. 47-57.

10. J. Liang, C. C. Chiau, X. Chen, and C. G. Parini, "Study of a Printed Circular Disc Monopole Antenna for UWB Systems", IEEE Transactions on Antennas and Propagation, vol. 53, no. 11, Nov. 2005, pp. 3500-3504.

11. G. S. Rao, S. S. Kumar and R. Pillalamarri, "Printed planar circular radiating patch ultra wideband antennas", Microsystem Technology, vol. 21, issue 11, Oct. 2014, pp. 2321-2325.

\section{Published By:}

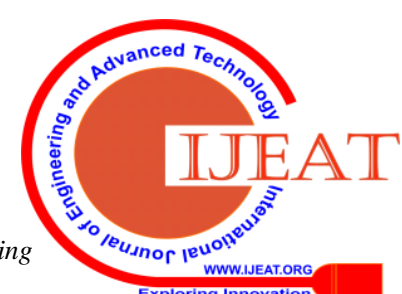




\section{An Equilateral Arm Inverted U-Slot and Notch Loaded UWB-CPMA with Rendered Ground Plane}

12. M. Moosazadeh, C. Ghobadi and Z. Esmati, "Monopole Antenna based on Wrench- shaped slot on Circular Disc Patch for UWB application", Microwave Optical Technology Letters, vol. 53, no. 8, Aug. 2011, pp. 1927-1931.

13. .K. Sharma, D. K. Upadhyay, H. Parthasarthy and R. Gurjar, "Wideband Slotted Circular Monopole Antenna with Saturn-Shaped Notch in Ground Plane," Applications of Artificial Intelligence Techniques in Engineering, vol. 698, 2019, pp, 143-154.

14. S. Kundu, "Experimental Study of a Printed Ultra-Wideband modified Circular Monopole Antenna", Microwave Optical Technology Letters, vol. 61, issue 5, 2019, pp. 1388-1393.

15. G. S. Rao, S. S. Kumar and R. Pillalamarri, "Small modified printed planar ultrawide band disc antennas with etched ground plane", Microsystem Technology, vol. 21, issue 5, May 2014, pp. 1081-1086.

16. Anitha Peram, A. Subba Rami Reddy and M. N. Giri Prasad, "Miniaturized Single Layer Ultra Wide Band (UWB) Patch Antenna Using a Partial Ground Plane", Wireless Personal Communications, Feb. 2019 (doi.org/10.1007/s11277-019-06213-4).

17. N. C. Azenui and H. Y. D. Yang, "A Printed Crescent Patch Antenna for Ultrawideband Applications", IEEE Antennas and Wireless Propagation Letters, vol. 6, 2007, pp. 113-116.

18. S. Baudha and M. V. Yadav, "A novel design of a planar antenna with modified patch and defective ground plane for ultra-wideband applications", Microwave Optical Technology Letters, Vol. 61, issue 5, 2019, pp. 1320-1327.

19. A. A. Adam, S. K. A. Rahim, K. G. Tan and A. W. Reza, "Design of 3.1-12 GHz Printed Elliptical Disc Monopole Antenna with Half Circular Modified Ground Plane for UWB Application", Wireless Personal Communications, vol. 69, issue 2, April 2012, pp. 535-549.

20. R. Azim, M. T. Islam and N. Misran, "Microstrip Line-fed Printed Planar Monopole Antenna for UWB Applications", Arabian Journal of Science Engineering, vol. 38, issue 9, April 2013, pp. 2415-2422.

21. T. Ali, B. K. Subhash, S. Pathan and R. C. Biradar, "A compact Decagonal-shaped UWB Monopole Planar Antenna with Truncated Ground Plane", Microwave Optical Technology Letters, vol. 60, 2018, pp. 2937-2944.

22. B. Roy, S. K. Chowdhury, A. K. Bhattacharjee, "Symmetrical Hexagonal Monopole Antenna with Bandwidth Enhancement under UWB operations", Wireless Personal Communications, vol. 108, issue 2, May 2019, pp. 853-863.

23. K. Kamakshi, J. A. Ansari, A. Singh, M. Aneesh and A. K. Jaiswal, "A novel ultrawideband toppled trapezium shaped patch antenna with partial ground plane", Microwave Optical Technology Letters, vol.57, issue 8, Aug. 2015, pp. 1983-1986.

24. C. A. F. Torres, J. L. M. Monroy, H. L. Morales, R. A. C. Perez, and A. C. Tellez, "A novel Fractal Antenna based on the Sierpinski structure for Super Wide-Band applications", Microwave Optical Technology Letters, vol. 59, no. 5, May 2017, pp. 1148-1153.

\section{AUTHOR PROFILE}

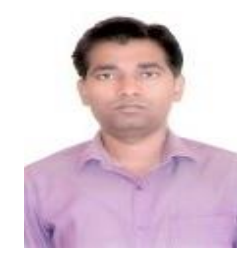

Mukesh Kumar was born in 1985 in Katihar, Bihar, India. He received his B.T.ech degree in Electronics and Communication Engineering in 2007 and M.Tech degree in Advance Communication System in 2010 from Sam Higginbottom University of Agriculture, Technology and Sciences (Formerly known as A.A.I-DU), Allahabad, U.P, India. He is presently Pursuing Ph.D. from J. K. Institute of Applied Physics and Technology, University of Allahabad, U.P., India. His research area includes signal processing, broadband and UWB microstrip patch antenna.

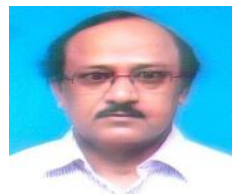

Jamshed Aslam Ansari was born in 1966 in Gahmar, Ghazipur UP, India. He received the B.Sc. and B.Tech. degrees in Electronics and Telecommunications from University of Allahabad, Allahabad, India. He received M.Tech. degree in Communication Systems from the Institute of Technology (Now, IIT), Banaras Hindu University (BHU), Varanasi, India, in 1991, and the Ph.D. degree from Mahatma Gandhi Chitrakoot Gramodaya Vishvavidyalaya, Chitrakoot (Satna), India, in 2000. He has published more than 200 papers in different national and international journals and conference proceedings. His current area of research is microstrip antenna, millimeter wave, and fiber optics. He is presently working as a Professor in the Department of Electronics and Communication, University of Allahabad.

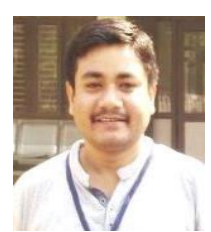

Abhishek Kumar Saroj was born in Kaushambi, U.P. India, in June 1988. He received B.Tech. degree in Electronics and Communication from BBS College of Engineering and Technology, Allahabad, affiliated to U.P.T.U., U.P., India, in 2010. He completed M.Tech. in Computer Technology from J. K. Institute of Applied Physics and Technology, University of Allahabad, Allahabad, UP, India, in 2015. He is currently pursuing Ph.D. from Department of Electronics and Communication, J.K. Institute of Applied Physics and Technology, University of Allahabad, Allahabad, UP, India. His research area includes microstrip antenna designing, smart antenna, advanced wireless communication systems, embedded system design, soft-computing techniques.

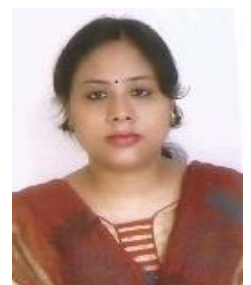

Rohini Saxena was born in 1983 in Bareilly, U.P, India. She received her B.T.ech degree in Electronics and Communication Engineering in 2007 and M.Tech degree in Advance Communication System in 2009 from Sam Higginbottom University of Agriculture, Technology and Sciences (Formerly known as A.A.I-DU), Allahabad, U.P, India. She is presently Pursuing Ph.D. from J. K. Institute of Applied Physics and Technology, Allahabad University, U.P., India. Her research area includes Artificial Neural Network, Wideband and UWB microstrip Patch antenna optimization using ANN. 